\title{
MULHERES E HERANÇAS EDUCATIVAS DO ANALFABETISMO
}

\author{
Marileia Gollo de Moraes ${ }^{1}$ \\ Maria Simone Vione Schwengber ${ }^{2}$ iD
}

\begin{abstract}
Resumo
São recorrentes as constatações de que os índices de analfabetismo retratam a dívida educacional brasileira, pois gerações de diferentes estratos de renda vivenciaram o acesso desigual à escolarização. Assim, historicamente, associa-se analfabetismo com termos que sugerem tratamento, reparos, cura, erradicação. Essa pesquisa coloca em evidência outras dimensões da "dívida educacional": trata o analfabetismo como herança educativa e traz as mulheres egressas do Programa Mulheres Mil como foco de análise. Estuda o que se sabe dessas mulheres enquanto grupo social participante do Programa, analisando os principais documentos dessa política: Termo de Cooperação (2006), Base Legal (s.d.), Guia Metodológico (s.d.) e Cartilha (2014). Operacionaliza metodologicamente com a análise do discurso foucaultiano a partir das "coisas ditas" pelas mulheres em entrevista narrativa, na direção de constituir um percurso analítico entre as aproximações discursivas em correlação com diferentes campos discursivos. Identifica as implicações sociais, históricas, políticas e culturais que compõem a herança educativa do analfabetismo.
\end{abstract}

Palavras-chave: Mulheres; Analfabetismo; Análise de Discurso; Heranças Educativas

\section{WOMEN AND THE EDUCATIONAL HERITAGE OF ILLITERACY}

\begin{abstract}
${ }^{1}$ Marileia Gollo de Moraes, Licenciada em Pedagogia e Especialista em Educação Infantil e Anos Iniciais (URICampus Erechim), Mestre em Educação (UFRGS) e Doutoranda do Programa de Mestrado e do Doutorado em Educação nas Ciências (UNIJUÍ), Ijuí/RS. Professora do IF Farroupilha - Campus Santo Augusto/RS. Participante do Grupo de Estudos em Política e Gestão Educacional e do Grupo Tecnologias Educacionais e Formação de Professores, vinculados ao IF Farroupilha. Endereço completo: Rua Amador Alves da Silva, 361. Bairro São Francisco. Santo Augusto/RS. CEP: 98590-000. E-mail: marileia.moraes@iffarroupilha.edu.br

${ }^{2}$ Maria Simone Vione Schwengber. Doutora em Educação pela UFRGS. Professora do Programa de Mestrado e do Doutorado em Educação nas Ciências e Professora do Curso de Educação Física da Universidade Regional do Noroeste do Estado do Rio Grande do Sul (Unijuí), Ijuí/RS. Participante do Grupo de Estudos de Educação e Relações de Gênero (Geerge), vinculado ao PPG-EDU da UFRGS e do grupo Grupo de Pesquisa Paidotribas, da Unijuí. Endereço completo: Rua José Bonifácio, 1521 - Centro. Ijuí/RS Cep 98700-000. E-mail: simone@unijui.edu.br
\end{abstract}

Revista Reflexão e Ação, Santa Cruz do Sul, v. 25, n. 2, p. 233-249, Maio./Ago. 2017.

http://online.unisc.br/seer/index.php/reflex/index 
The observations that illiteracy rates portrait the Brazilian educational debt are common because different income strata have had unequal access to schooling throughout generations. Therefore, illiteracy has historically been associated with terms that suggest treatment, repair, cure, eradication. This research puts in evidence other dimensions of this "educational debt": it treats illiteracy as educational heritage and places the women that have concluded the Program Mulheres Mil (Thousand Women) as the main focus of analysis. It studies what is known about these women as a social group that attend this Program, analyzing the main documents related to this public policy: Cooperation Therm (2016), Legal Base (s.d), Methodological Guide (s.d), and Primer (2014). The methodological operationalization uses Foucault's discourse analysis on the "things said" by these women in narrative interviews, in the direction of constructing an analytical route between the discursive approximations in correlation with different discursive fields. It identifies social, historical, political, and cultural implications that form the educational heritage of illiteracy.

Keywords: Women; Illiteracy; Discourse Analysis; Educational Heritage

\title{
MUJERES Y LAS HERENCIAS EDUCATIVAS DEL ANALFABETISMO
}

\begin{abstract}
Resumen
Son recurrentes las constataciones de que los índices de analfabetismos retratan la deuda educativa brasileña, pues generaciones de distintos estratos de ingresos vivenciaron el acceso desigual a la enseñanza. Así, históricamente, se asocia analfabetismo con termos que sugieren tratamiento, reparos, cura, erradicación. Esa búsqueda pone en evidencia otras dimensiones de la "deuda educativa": trata el analfabetismo como herencia educativa y trae las mujeres egresas del "Programa Mulheres Mil" como foco de análisis. Estudia lo que se sabe de esas mujeres en cuanto grupo social participante del programa, analizando los principales documentos de esa política: Acuerdo de Cooperación (2006), Base Legal (s.d), Guía Metodológica (s.d) y Cartilla (2014). Instrumentaliza metodológicamente con el análisis del discurso foucaultiano a partir de las "cosas dichas" por las mujeres en entrevista narrativa en
\end{abstract}


correlación con distintos campos discursivos. Identifica las implicaciones sociales, históricas, políticas y culturales que componen la herencia educativa del analfabetismo.

Palabras-claves: Mujeres; Analfabetismo; Análisis de Discurso; Herencias Educativas

\section{INTRODUÇÃO}

A problematização das heranças educativas do analfabetismo de um grupo de mulheres constitui o objetivo dessa escrita. Está pautada em escolhas discursivas e metodológicas que solicitam a exposição de alguns pressupostos quanto: ao termo herança educativa, na contramão de como tem sido tratado historicamente o tema do analfabetismo, ao termo mulheres num contexto de discussão de concepções mais alargadas de gênero e a análise do discurso na perspectiva dos enunciados.

O termo herança remete aos bens e direitos que se herda por disposição testamentária, sucessão, legado, ou ainda a cultura transmitida pelas gerações passadas. Tratar o analfabetismo como herança problematiza como ele tem sido nomeado, comumente, com termos que remetem à necessidade de "tratamento", "reparos", "cura" ou "erradicação". No pensamento de Ferraro (2004) uma sucessão de "desconceitos" (ignorância, cegueira, preguiça, doença, erva daninha, incapacidade, periculosidade etc.) que têm servido muito mais para desacreditar e estigmatizar talvez os/as analfabetos/as do que à causa da universalização da alfabetização no país. Por heranças educativas, compreendemos a relação com o outro, num determinado contexto, em que a ligação, a passagem e a transição entre os seus predecessores e seus sucessores é possibilitada através das transmissões educativas.

Quanto às questões conceituais de gênero, essa categoria de análise enfrentou uma trajetória difícil no campo historiográfico, assim como a inclusão do termo mulher ou mulheres. Acreditava-se que, ao falar de homens, as mulheres estariam sendo contempladas. Uma contraposição a essa modalidade de história iniciou com o grupo dos Annales (1920), mas foi em 1960 que as mulheres são alçadas à condição de objeto e sujeito da História, marcando a emergência da História das Mulheres pelo processo de transformações da historiografia (SOIHET; PEDRO, 2007). No final da década de 1970, firmado o antagonismo homem versus mulher, outra tensão se instaurou, não se acreditava mais numa identidade única entre as mulheres, reivindicou-se uma diferença dentro da diferença. 
Gênero segue sendo incorporado e utilizado como um conceito que se opõe ou complementa a noção de sexo biológico e se refere aos comportamentos, atitudes ou traços de personalidade que as culturas inscrevem sobre corpos sexuados. Tem sido usado, sobretudo pelas feministas pós-estruturalistas, para enfatizar que a sociedade forma não só a personalidade e o comportamento, mas também as maneiras como o corpo (e também o sexo) aparece (MEYER, 2004).

Optamos pelo termo mulheres porque elas são o foco da investigação ${ }^{3}$, e pelo conceito de gênero, na perspectiva pós-estruturalista, como suporte para a contextualização das suas heranças educativas. Porque gênero enfatiza essa pluralidade e conflitualidade dos processos pelos quais a cultura constrói e distingue corpos e sujeitos femininos e masculinos, torna-se necessário considerar que isso se expressa pela articulação de gênero com outras marcas sociais, como classe, raça/etnia, sexualidade, geração, religião, nacionalidade (MEYER, 2004; SCHWENGBER, 2006).

O percurso de análise envolveu a entrevista narrativa (SCHÜTZE, 2013) com sete mulheres egressas do Curso Higiene, Conservação e Produção de Alimentos do Instituto Federal Farroupilha (IFFAR) - Campus Santo Augusto/RS (Turma 2013), o tratamento adequado às falas ${ }^{4}$, no momento da transcrição, e a análise do discurso na perspectiva dos enunciados (FISCHER, 2001, 2012). A operacionalização da análise trata os discursos como conjuntos de acontecimentos discursivos. O acontecimento se efetiva no âmbito da materialidade, produz-se como efeito de e em uma dispersão material. O discurso funciona nas coisas ditas, na materialidade, e não como algo a ser interpretado (FOUCAULT, 1999).

Ponderados esses pressupostos, trazemos os elementos discursivos para compreender as heranças educativas do analfabetismo de um grupo de mulheres. Sistematizamos o que se sabe dessas mulheres, enquanto grupo social, participante do Programa Mulheres Mil (PMM) - 2011/2014, analisando as adjetivações atribuídas às mulheres, "público-alvo” da política pública, nos principais documentos: Termo de Cooperação (2006), Base Legal (s.d.), Guia Metodológico (s.d.) e Cartilha (2014). Apresentamos as aproximações discursivas das narrativas das participantes da pesquisa em correlação com diferentes campos discursivos: da

\footnotetext{
${ }^{3}$ Pesquisa de doutoramento no Programa de Mestrado e do Doutorado em Educação nas Ciências (UNIJUÍ), Ijuí/RS, articula-se com a pesquisa em rede (UFRGS, UNISINOS, UNIJUÍ e UFRB) aprovada pelo CNPq (2014) para financiamento no âmbito do Programa de Bolsas de Produtividade em Pesquisa - Bolsa PQ 1B: "Políticas públicas de inclusão social e transversalidade de gênero: ênfases, tensões e desafios atuais" coordenada pela professora Dr ${ }^{\mathrm{a}}$ Dagmar Estermann Meyer da UFRGS.

${ }^{4}$ Schwengber defende a revisão das transcrições de entrevistas (informação verbal). Devem ser fiel ao conteúdo, e não aos ditos "erros" de coloquialidade da fala e não revisá-las é um modo de marcar os sujeitos entrevistados.
} 
política pública, da história das mulheres nos aspectos da educação, da escolarização e possibilidades de trabalho formal e renda.

\section{ANÁLISE DO DISCURSO NA PERSPECTIVA DOS ENUNCIADOS}

Compreendemos o discurso como regimes de verdades que produzem identidades tomando a forma do discurso, a ser dito, enunciado (FOUCAULT, 1999). Também, como um conjunto de enunciados que se apoiam na mesma formação discursiva. Desenvolvemos um exercício de análise dos quatro elementos básicos do enunciado: o referente, o fato de ter um sujeito que pode afirmar efetivamente aquilo, o fato do enunciando não existir isolado, mas sempre em associação e correlação com outros enunciados do mesmo discurso (diferentes campos discursivos) e a materialidade do enunciado (FISCHER 2001, 2012).

$\mathrm{Na}$ análise do discurso, desde a perspectiva dos enunciados, nessa pesquisa, emergem como referentes as mulheres, público-alvo do PMM: mulheres com histórico de adultez precoce $^{5}$ refletindo na precarização dos processos de escolarização, de inserção no mundo do trabalho formal e de renda mínima. A análise da caracterização discursiva do perfil do público-alvo nos documentos do PMM, quanto às adjetivações atribuídas às mulheres, e da sistematização das narrativas das participantes da pesquisa permite afirmar a existência de sujeitos que confirmam um conjunto de marcas sociais que, ao mesmo tempo, as singularizam e as coletivizam. Além disso, os enunciados, na sua materialidade, estão em correlação com diferentes campos discursivos: da política pública e da história das mulheres.

\section{AS MULHERES - ALUNAS DO PROGRAMA MULHERES MIL}

O Programa Nacional Mulheres Mil - Educação, Cidadania e Desenvolvimento Sustentável, instituído nacionalmente pela Portaria $\mathrm{N}^{\circ} 1.015$, de 21 de julho de 2011, está inserido no Plano Brasil Sem Miséria $(\mathrm{BSM})^{6}$, e integra um conjunto de ações que consolidam as políticas públicas e diretrizes governamentais de inclusão educacional, social e produtiva de mulheres em situação de vulnerabilidade. É contemplado pelas ações da meta de erradicação da pobreza extrema no eixo inclusão produtiva urbana. Consta no Plano

\footnotetext{
${ }^{5}$ Assumiram, antecipadamente, atividades que caracterizam a entrada na vida adulta: trabalhar, responsabilizarse com a casa, com o cuidado para com a família, contribuir com a renda familiar, compor a própria família, casar, sustentar-se por conta própria. (MORAES, 2005).

${ }^{6}$ Decreto $\mathrm{n}^{\mathrm{0}} 7.492$, de 2 de junho de 2011, organiza suas ações em três eixos: garantia de renda, acesso a serviços e inclusão produtiva, com vertentes rural e urbana.
}

Revista Reflexão e Ação, Santa Cruz do Sul, v. 25, n. 2, p. 233-249, Maio./Ago. 2017.

http://online.unisc.br/seer/index.php/reflex/index 
Plurianual (PPA 2012/2015) e também no III Plano Nacional de Políticas para as Mulheres do Governo Federal. Porém, desde 2005 foi desenvolvido como um projeto piloto entre CEFETRN (Natal) e o Niagara College ${ }^{7}$, e em 2007, como programa de cooperação técnica entre o Brasil e o Canadá, nos estados da Rede Norte e Nordeste de educação tecnológica ${ }^{8}$.

Em 2012, expandiu-se para as demais regiões do país, quando o IFFAR iniciou a oferta, reunindo cem mulheres no campus Santo Augusto/RS. E mais cem mulheres no ano de 2013 no curso de Higiene, Conservação e Produção de Alimentos. Em 2014, o Ministério do Desenvolvimento Social e Combate à Fome (MDS) e o Ministério da Educação (MEC) integraram o PMM ao Programa Nacional de Acesso ao Ensino Técnico e ao Emprego (PRONATEC)/BSM. A regulamentação dessa política pública consta no Termo de Cooperação da Proposta de Projeto Mulheres Mil (BRASIL, 2006), Base Legal do PMM (s.d.), Guia Metodológico do Sistema de Acesso, Permanência e Êxito das Mulheres Mil (s.d.) e Cartilha PRONATEC/ BSM/Mulheres Mil (2014) ${ }^{9}$.

O primeiro documento, Termo de Cooperação entre The Association of Canadian Community Colleges e o Conselho dos Dirigentes dos Centros Federais de Educação Tecnológica, intitulado Proposta de Projeto Mulheres Mil: educação, cidadania e desenvolvimento sustentável (BRASIL, 2006), ao longo das sessenta e três páginas, adjetiva as mulheres como "desfavorecidas" e "marginalizadas". Trazemos, apenas, alguns trechos: "O projeto atenderá o objetivo global da inclusão social e econômica de mulheres desfavorecidas [...]" (BRASIL, 2006, p. 2, grifos nossos); “Os parceiros brasileiros acreditam fortemente que em um período de quatro anos possam desenvolver uma infra-estrutura e sistema de acesso e capacitação sustentável para atender as mulheres marginalizadas [...].” (BRASIL, 2006, p. 10-11, grifos nossos).

As mulheres também são caracterizadas como "população-alvo tradicionalmente bastante difícil de ser atingida e encaminhada para um estabelecimento de ensino" (BRASIL, 2006, p. 35). Ainda, como mulheres "com questões de analfabetismo, educação deficiente, histórias de emprego de baixo nível ou informais e a constante realidade da pobreza" (BRASIL, 2006, p.8). É possível identificar no objetivo do projeto uma projeção na mulher

\footnotetext{
${ }^{7}$ Faculdade no sul de Ontário (Canadá), uma das pioneiras em implementar práticas ARAP, conduziu no Brasil o Projeto Piloto ARAP (Avaliação e Reconhecimento de Aprendizagem Prévia) em 2005/2006. (BRASIL, 2006).

${ }^{8}$ Norte: Amazonas, Roraima, Tocantins. Nordeste: Alagoas, Bahia, Ceará, Maranhão, Rio Grande do Norte, Sergipe, Paraíba, Pernambuco, Piauí. A sistematização do projeto piloto encontra-se disponível em < http://portal.mec.gov.br/programa-mulheres-mil/projeto-piloto> Acesso em 11 de setembro de 2016.

9 Disponíveis nos sites https://map.mec.gov.br/projects/mulheres-mil/documents e http://portal.mec.gov.br/programa-mulheres-mil/pronatec-mulheres-mil com exceção do primeiro documento concedido, de forma impressa, pela gestora do Projeto Desenvolvimento Comunitário - Mulheres Mil do IFPB.

Revista Reflexão e Ação, Santa Cruz do Sul, v. 25, n. 2, p. 233-249, Maio./Ago. 2017.
}

http://online.unisc.br/seer/index.php/reflex/index 
como aquela que, além de transformar a si mesma, contribui para o avanço de sua família e de sua comunidade: "Promover a inclusão social e econômica das mulheres desfavorecidas no nordeste e norte do Brasil, permitindo-lhes melhorar o seu potencial produtivo, suas vidas e as vidas de suas famílias e comunidades” (BRASIL, 2006, p. 25).

A Base Legal (s.d.) adjetiva as mulheres, nas vinte páginas do documento, com as expressões que definem o seu público-alvo: “mulheres de baixa renda, vulneráveis socialmente e de baixo nível de escolaridade; moradoras de comunidades integrantes dos Territórios da Cidadania e/ou com baixo índice de desenvolvimento humano" (BRASIL, s.d. p.2). Demarcamos alguns trechos: o primeiro objetivo - "Estimular a inclusão educacional, produtiva e social de mulheres em situação de vulnerabilidade" (BRASIL, s.d. p. 9, grifos nossos); e a meta - "Entre 2011 e 2014 o Projeto prevê a formação de 100 mil mulheres moradoras de comunidades com baixo índice de desenvolvimento humano e/ou integrantes dos Territórios da Cidadania" (BRASIL, s.d. p. 9, grifos nossos).

No Guia Metodológico do Sistema de Acesso, Permanência e Êxito das Mulheres Mil (s.d.), elaborado pelos servidores dos Institutos Federais participantes dos projetos pilotos, em suas quarenta e oito páginas, o termo mulheres é raramente adjetivado. Se adjetivado, é acompanhado pelas expressões "em situação de vulnerabilidade social", "alunas do Programa", "mulheres pertencentes às classes menos favorecidas e com histórico de descontinuidade educacional em nível fundamental", "mulheres desfavorecidas".

Destacamos alguns trechos: a apresentação - “[...] visando à formação educacional, profissional e cidadã de mulheres desfavorecidas das regiões Norte e Nordeste do Brasil" (BRASIL, s.d. p. 4, grifos nossos); a contextualização - "pela melhoria do acesso de mulheres em situação de vulnerabilidade social à educação e ao mundo do trabalho" (BRASIL, s.d. p. 5, grifos nossos); os cursos possíveis - "Considerando-se a realidade do público do programa, a situação das mulheres pertencentes às classes menos favorecidas e com histórico de descontinuidade educacional em nível fundamental [...]” (BRASIL, s.d. p. 24, grifos nossos); o módulo permanência e êxito - “dar suporte, em forma de serviços e espaços, às mulheres alunas do Programa [...]; cuidar para que o ambiente e as pessoas acolham e respeitem as mulheres do Programa" (BRASIL, s.d. p. 27, grifos nossos).

Na Cartilha PRONATEC/BSM/Mulheres Mil (2014) as mulheres vêm adjetivadas, no decorrer das vinte e quatro páginas, como "pobres em situação de maior vulnerabilidade", "em situação de pobreza", "mais pobres", "beneficiárias do Programa Bolsa Família", "historicamente em situação de extrema pobreza e vulnerabilidade", "que trabalham 
informalmente”, “em situação de extrema pobreza”, “em situação de risco, vulnerabilidade e extrema pobreza".

Pontuamos alguns trechos: “Ao promover a formação educacional, profissional e cidadã de mulheres pobres em situação de maior vulnerabilidade, [...] qualificar profissionalmente mulheres em situação de pobreza" (BRASIL, 2014, p. 3-4, grifos nossos); “o Pronatec/BSM Mulheres Mil amplia a oferta de qualificação profissional às mulheres mais pobres, em especial às beneficiárias do Programa Bolsa Família" (BRASIL, 2014, p. 4, grifos nossos); "busca possibilitar o acesso, com exclusividade, de mulheres historicamente em situação de extrema pobreza e vulnerabilidade à educação profissional e tecnológica" (BRASIL, 2014, p. 4, grifos nossos); “[...] é possível identificar grupos de mulheres que trabalham informalmente e que não têm nenhuma relação com o mercado de trabalho formal [...]" (BRASIL, 2014, p. 5).

Os adjetivos atribuídos às mulheres, nos diferentes documentos, vêm sendo incorporados dando uma ideia de complementaridade. De "marginalizadas e desfavorecidas" constantes no projeto do Programa (2006), para "vulneráveis", "baixa renda e classes menos favorecidas" na Base Legal (s.d.) e Guia metodológico (s.d.). Já no documento atual do PRONATEC/BSM/Mulheres Mil (2014) as expressões "vítimas de violência", "risco social" e "pobreza" foram acrescentadas na definição do público-alvo:

Mulheres a partir de 16 anos, chefes de família, em situação de extrema pobreza, cadastradas ou em processo de cadastramento no CadÚnico, com as seguintes características: em vulnerabilidade e risco social, vítimas de violência física, psicológica, sexual, patrimonial e moral, com escolaridade baixa ou defasada e, preferencialmente, ainda não atendidas pelo Pronatec/BSM. (BRASIL, 2014, p. 6).

Conforme a política pública se fortalece, a caracterização do público-alvo recebe detalhamento das especificidades: classe social, renda, idade, grau de escolaridade, ocupação, etc. Quanto às heranças educativas, desde o primeiro documento transparece a preocupação com os processos históricos de escolarização, nos seguintes termos: "Mulheres com questões de analfabetismo, educação deficiente" (BRASIL, 2006, p. 8), "baixo nível de escolaridade" (BRASIL, s.d, p.2), "histórico de descontinuidade educacional em nível fundamental" (BRASIL, s.d., p. 24) e “escolaridade baixa ou defasada” (BRASIL, 2014, p. 6).

\section{AS HERANÇAS EDUCATIVAS DO ANALFABETISMO}


As mulheres que escolhemos como sujeitos da pesquisa, viveram sua infância nas décadas de 50 e 60 do século XX, contexto onde aproximadamente $50 \%$ da população brasileira acima dos quinze anos de idade era analfabeta, proveniente da insuficiência de políticas públicas direcionadas ao financiamento da educação. A relação das mulheres com a escola varia entre nenhum vínculo (três delas), até seis anos de matrícula. Período, esse, que não permitiu ultrapassar o terceiro ano do Ensino Fundamental ${ }^{10}$ (duas cursaram o primeiro ano, uma cursou até o terceiro ano e uma cursou alfabetização na modalidade de educação de jovens e adultos - EJA). Assim mesmo, todas se declararam analfabetas, justificando o fato de não saberem ler e escrever, com acontecimentos nas suas histórias de vida: não ter ido à escola por morar longe, dificuldades de aprendizagem como "fraqueza" ou "burrice", problemas de saúde, impedimento de frequentar turmas de alfabetização de adultos (período noturno, implicância do marido, dedicação ao cuidado com os netos, etc.).

No discurso de Norma ${ }^{11}$ e Ester localizamos esses elementos:

Norma (71 anos): Venho de uma família pobre, de dez irmãos. Morava longe, frequentei a aula só uma semana porque quando chovia o rio enchia e nós ficávamos presos lá na escola. Casei e viria frequentar as aulas, mas o meu marido não deixava! Dizia que eu não tinha que ir. Teria que trabalhar de dia pra ajudar a comprar a comida pras crianças [...] de noite tinha aula, e de noite ele não aceitou! E essa é a razão que hoje eu não sei.

Ester (61 anos): Aos 7 anos, meu pai me matriculou na escola e frequentei até os 13 anos. Não aprendi [...] fiquei no primeiro ano e rodava [...]. Quando passei pro segundo ano, o pai me tirou da escola. Porque estava grandona e tinha que trabalhar. A mãe e 0 pai diziam: que burra, não aprende [...], sempre rodando!

A condição de terem frequentado a escola e mesmo assim assumirem-se analfabetas, pode também estar associado ao fato de que, realmente, não aprenderam a ler e escrever ou ainda ao analfabetismo por regressão. Segundo Ribeiro (1997), esta é uma característica dos grupos que, tendo alguma vez aprendido a ler e escrever, devido ao não uso dessas habilidades, retornam à condição de analfabetos.

\footnotetext{
${ }^{10}$ Nomenclatura da legislação atual. Na época, a estrutura do ensino, normatizada pela Lei Orgânica $n^{\circ} 8.529 / 46$ e após pela Lei de Diretrizes e Bases 4.024/61, estabelecia quatro séries anuais para o grau primário. Por isso muitas se referem ao "primário incompleto". Concluindo o grau primário, era obrigatório o exame de admissão ao primeiro ciclo Grau Médio ou Ensino Secundário, o ginasial com duração de quatro séries.

${ }^{11}$ Receberam nomes fictícios por questões éticas da pesquisa.
}

Revista Reflexão e Ação, Santa Cruz do Sul, v. 25, n. 2, p. 233-249, Maio./Ago. 2017.

http://online.unisc.br/seer/index.php/reflex/index 
As mulheres justificam a falta de oportunidade de não terem estudado e questionam as diferenças entre a educação dos meninos e das meninas, numa época em que seus pais tinham dificuldade em imaginar para elas um futuro diferente do que foi o seu passado. "O passado dos adultos é o futuro de cada nova geração”, afirma Forquin (2003, p. 6), ao se referir as culturas pós-figurativas ${ }^{12}$. Localizamos aqui o recorte de gênero e geração das heranças educativas do analfabetismo:

Rosalina: (45 anos): $O$ meu avô nem deixava irmos ao colégio. Só pra trabalhar. Nós nunca aprendemos a ler. Não sei ler nada. Se chegar um papel, eu não sei ler porque a gente não teve oportunidade no colégio.

Isaura (66 anos): Só os guris, menina não podia nem falar em estudar. Por que será que era assim? Por que será que o tempo antigo era assim?

As orientações da família quanto ao destino ideal das mulheres, ou das mulheres ideais, representavam o pensamento da época, o qual constava até em decreto presidencial assinado por Getúlio Vargas em 1941: “a educação feminina deveria formar mulheres 'afeiçoadas ao casamento, desejosas da maternidade, competentes para a criação dos filhos e capazes na administração da casa"” (DEL PRIORE, 2013, p. 66). Nesse contexto, somente a partir de 1943 “a legislação concedeu permissão para a mulher casada trabalhar fora de casa, 'sem a autorização expressa do marido"” (DEL PRIORE, 2013, p. 68). "Sem estudo, a maior parte das jovens investia nas 'prendas domésticas'.” (DEL PRIORE, 2013, p. 69).

A divisão entre a esfera pública masculina e os recônditos da vida privada essencialmente femininos, não contemplou a realidade de todas as mulheres. "Há centenas de anos, a mulher brasileira trabalha. Nos primórdios da colonização, elas foram fazendeiras, comerciantes, lavadeiras, escravas. Na primeira metade do século $\mathrm{XX}$, grande parte do proletariado era formada por mulheres." (DEL PRIORE, 2013, p. 89). Na década de 50, com o crescimento urbano e industrial, aumentaram as possibilidades educacionais e profissionais para as mulheres no Brasil. Porém, as mudanças não tinham atingido as mentalidades e tanto as distinções entre posições femininas e masculinas quanto a moral sexual permaneciam nítidas. O "trabalho da mulher, ainda que cada vez mais comum, era cercado de preconceitos e visto como subsidiário ao trabalho do 'chefe da casa'.” (DEL PRIORE, 2013, p. 71).

\footnotetext{
${ }^{12}$ Forquin (2003) remete ao estudo de Margaret Med sobre o fosso entre gerações onde é apresentada a distinção entre três tipos de culturas: culturas pós-figurativas, co-figurativa e pré-figurativa.
}

Revista Reflexão e Ação, Santa Cruz do Sul, v. 25, n. 2, p. 233-249, Maio./Ago. 2017.

http://online.unisc.br/seer/index.php/reflex/index 
As heranças educativas do analfabetismo das mulheres têm um recorte de tempo, gênero, classe social, geração e etnia que emergem de um contexto histórico, social e político. Segundo Rosemberg (2013) foi longo o processo para a permissão legal do acesso geral e irrestrito das brasileiras à escola. Autorizada em 1827 pela Lei Geral do Ensino de 5 de outubro, restrita apenas às escolas femininas de primeiras letras, essa barreira legal só foi rompida em 1971 com a Lei de Diretrizes e Bases da Educação. Desde o primeiro recenseamento em 1872, até o de 1950, vem denotando o analfabetismo de mulheres em vários pontos percentuais maiores que os dos homens. Uma redução gradual do diferencial foi ocorrendo a partir de então, chegando a equiparar-se em 1985 (26,6\% dos homens e 26,6\% das mulheres) até sua inversão detectada no início dos anos 1990. Época em que a educação das mulheres entrou na agenda da educação nacional, como em outros países da América Latina deflagrando um "intenso processo de reformas educacionais impulsionadas por organizações internacionais (UNESCO, UNICEF, Banco Mundial, entre outras), subsumidas nos compromissos da campanha internacional "Educação para Todos"” (ROSEMBERG, 2013, p.345).

\subsection{Transições e novas configurações discursivas nas heranças educativas das mulheres}

O tráfego feminino nos espaços públicos, pela via do trabalho remunerado, afirmou-se nos anos 80 do século XX, rompendo um ciclo na educação das meninas - para serem mulheres preferencialmente casadas, mas independentes. "A mulher casada brasileira rompeu um ciclo - fora educada pela mãe de modo muito semelhante ao que já ensinara a avó, no entanto dava à filha conselhos que construiriam gerações de mulheres diferentes." (DEL PRIORE, 2013, p. 83). As mães redimensionaram seu discurso na educação das filhas, projetando para elas um futuro diferente do seu presente e do legado de três gerações. Isso reflete nas heranças, dentre elas a escolarização. Mães analfabetas ou com escolaridade mínima (assim como as participantes dessa pesquisa) também puderam incentivar as filhas a continuarem os estudos, a conquistarem espaço no mundo do trabalho e possivelmente a independência financeira.

A partir da década de noventa, o Estado brasileiro implementou políticas sociais ${ }^{13}$ voltadas aos direitos sociais de crianças e adolescentes pobres. As possibilidades de

\footnotetext{
${ }^{13}$ Bolsa Família - Lei Federal $n^{\circ} 10.836$, de 9 de janeiro de 2004 regulamentado pelo Decreto $n^{\circ} 5.209$, de 17 de setembro de 2004; o Programa Social de Erradicação do Trabalho Infantil (PETI) e o PROJOVEM instituído pela Lei No 11.129, de 30 de junho de 2005.

Revista Reflexão e Ação, Santa Cruz do Sul, v. 25, n. 2, p. 233-249, Maio./Ago. 2017.

http://online.unisc.br/seer/index.php/reflex/index
} 
escolarização para as meninas e mulheres se ampliaram, com um conjunto de incentivos para concluir o ensino secundário (AREND, 2013) confirmando o recorte de classe social das heranças educativas do analfabetismo e como as implicações discursivas políticas as influenciam. Nesse sentido, cabe acrescentar os programas redesenhados pelo BSM, a partir de 2011, realizados em interação e parceria entre o MDS e o MEC,

No eixo da garantia de renda, a principal iniciativa é o Programa Bolsa Família, cabendo ao MEC o acompanhamento da condicionalidade em educação. Ainda neste item, o acompanhamento do Benefício de Prestação Continuada (BPC) conta com o apoio do MEC na realização do controle anual dos beneficiários. No eixo da inclusão produtiva, cabe ao MEC a oferta de cursos de qualificação profissional por meio do Programa Nacional de Acesso ao Ensino Técnico e Emprego (Pronatec). Por fim, no eixo de acesso a serviços, temos a Ação Brasil Carinhoso. (FERNANDES, 2014, p. 544-545).

A possibilidade de independência das mulheres articulou-se com trabalho remunerado, escolarização e formação profissional compondo novas configurações discursivas nas experiências sociais, constatadas nas estatísticas ${ }^{14}$ sobre a presença das mulheres, em ocupações do mundo do trabalho historicamente exercidos por homens e com níveis de escolaridade cada vez mais avançados.

As mudanças discursivas a respeito das mulheres, nos âmbitos público e privado, não atingem todas as mulheres nem nas mesmas proporções. Há atravessamentos quanto à etnia, geração, religião, orientação sexual, classe social, país de origem. Em nível mundial, a meta de promoção de igualdade de gênero e autonomia das mulheres, registrou avanços na educação, emprego e participação parlamentar. E como desafios, seguem a eliminação da violência contra mulheres e meninas; a igualdade de oportunidades, recursos e responsabilidades entre homens e mulheres; a participação das mulheres em pé de igualdade em todos os âmbitos, desde a casa, os negócios até o parlamento (ONU, 2014-2015).

Da análise das narrativas discursivas em correlação aos estudos sócio-histórico-políticoculturais da educação das mulheres no Brasil, sem pretensão de generalização, consideramos as mulheres desse estudo como exemplaridade de uma geração de mulheres analfabetas. Durante séculos, o Estado brasileiro fora eficiente em manter as mulheres afastadas da educação pública, confirmando a raiz histórica da herança educativa do analfabetismo. Sem as antigas restrições e impulsionadas por mudanças econômicas e culturais, incluindo os feminismos, (ROSEMBERG, 2013) as estatísticas e as proposições de políticas públicas,

\footnotetext{
14 Síntese dos Indicadores Sociais $\quad$ (SIS) 2015, disponível em
} http://biblioteca.ibge.gov.br/visualizacao/livros/liv95011.pdf Acesso em fevereiro 2016.

Revista Reflexão e Ação, Santa Cruz do Sul, v. 25, n. 2, p. 233-249, Maio./Ago. 2017.

http://online.unisc.br/seer/index.php/reflex/index 
nesse caso a Síntese dos Indicadores Sociais (SIS) (BRASIL, 2015) e o III Plano Nacional de Política para Mulheres (PNPM) (BRASIL, 2013) denotam um contexto diferente, mas ainda problemático.

No Brasil foram registrados avanços nos dados relativos à educação, porém as heranças educativas do analfabetismo continuam nas estatísticas, em proporções cada vez menores, mas ainda 8,3\% da população estão nesse cômputo. O Brasil está entre os nove países que ficaram longe da meta de alfabetização da população adulta, em 95\% até o final do ano de 2015, e que realizam progressos lentos no período avaliado de 2000 a 2011. Inclusive, o Plano Nacional de Educação (PNE) 2014-2021 em sua meta 9 propõe elevar a taxa de alfabetização da população com quinze anos ou mais para 93,5\% até 2015 e, até o final da vigência do PNE, erradicar o analfabetismo absoluto e reduzir em 50\% a taxa de analfabetismo funcional (BRASIL, 2014 ).

A maior incidência de analfabetismo ocorre entre homens $(8,8 \%)$, entre os de cor preta ou parda $(11,5 \%)$ e entre aqueles com idade acima dos 65 anos (27,7\%). Outras dimensões pertinentes são a renda, a região de residência e situação do domicílio. A taxa de analfabetismo é maior entre os que residem na Região Nordeste (16,9\%), entre aqueles que estão nas áreas rurais $(20,8 \%)$ e entre aqueles que pertencem ao quinto mais pobre $(13,9 \%)$, (BRASIL, SIS, $2014^{15}$ ). A situação das participantes da pesquisa converge com essa constatação, quanto o perfil etário (uma tem 45 anos e seis têm mais de sessenta anos de idade) reafirmando a incidência de analfabetismo entre os mais velhos. Também, nos fatores da renda familiar mensal, que não ultrapassa um salário mínimo (oriunda de trabalho informal, aposentadoria, ou dependência direta do companheiro) e ainda pela origem rural apenas uma delas sempre morou na cidade. Completamos, aqui, o conjunto de marcas sociais que viemos demarcando nesse estudo quanto às heranças educativas do analfabetismo: a questão da etnia, geração, classe social, situação de domicilio.

Quanto à questão geracional, identificamos no III PNPM ${ }^{16}$ da Secretaria de Políticas para Mulheres (SPM) um discurso na perspectiva do capital humano. No que se refere às diferentes intenções em relação às mulheres mais jovens, como a ampliação do acesso e

\footnotetext{
${ }^{15}$ Foi utilizada a SIS (2014), pois a SIS (2015) não apresenta essas especificidades do analfabetismo.

${ }^{16}$ A criação da SPM, em 2003, e as três Conferências Nacionais de Política de Mulheres (2004, 2007 e 2011$)$ referendaram os três PNPM (2004-2007, 2008-2011, 2013-2015) e esses reafirmam os princípios da Política Nacional para Mulheres: autonomia das mulheres em todas as dimensões da vida; busca da igualdade efetiva entre mulheres e homens, em todos os âmbitos; respeito à diversidade e combate a todas as formas de discriminação; caráter laico do Estado; universalidade dos serviços e benefícios ofertados pelo Estado; participação ativa das mulheres em todas as fases das políticas públicas; transversalidade como princípio orientador de todas as políticas públicas. (BRASIL, 2013).
} 
permanência das mesmas no Ensino Profissional, Tecnológico e no Ensino Superior, "com destaque para as áreas científicas e tecnológicas, com igualdade de gênero, raça, etnia, considerando as mulheres em sua diversidade" (BRASIL, 2013-2015, p. 23). Enquanto que para as mulheres acima de 50 anos, negras e indígenas, a meta é a redução do analfabetismo. $\mathrm{Na}$ perspectiva do desenvolvimento humano, projetos educacionais comprometem-se com a cidadania plena, ampliação da qualidade de vida e a possibilidade de novos significados à existência humana, indiferente da etapa do ciclo da vida do sujeito e do retorno a ser dado à economia.

\section{CONSIDERAÇÕES FINAIS}

As heranças educativas do analfabetismo, que permitem reconhecer as mulheres participantes da pesquisa como parte de uma geração de adultas analfabetas, emergem de um contexto histórico, social e político em que a escolarização das mulheres praticamente não existiu por questões culturais da época, de supervalorização do trabalho, do lugar destinado às mulheres, associados à precariedade das políticas educacionais, e de um modo dos pais projetarem às futuras gerações a responsabilidade de sua fiel substituição. Não bastasse esse contexto de raiz, que vai se modificando com mais força na década de noventa do século XX, as mulheres também são herdeiras da ausência, da assistematicidade e da política do voluntariado dos programas de educação de adultos, as quais em geral emergem como políticas de governo brasileiro.

De algum modo, dialogam com essas heranças, ao questionarem sua condição de crianças antecipadas ao mundo adulto, das diferenças na educação de meninos e meninas e ao buscarem a educação de jovens e adultos se deparando com as implicações da escolarização "tardia": os mitos em torno da aprendizagem na vida adulta, as situações reais de dificuldades, o sentimento de deslocamento num espaço onde transita um público infantil e jovem. Também, ousam ao reconhecerem a possibilidade de participar dos cursos de qualificação profissional do PMM, construindo estratégias para desenvolver as atividades que envolvem leitura e escrita. E diferente dos seus antepassados, projetarem para as suas filhas uma melhor posição social, já que as políticas públicas avançaram significativamente no decorrer dos últimos anos.

O que nos permite dizer que a herança, o herdado, é aquilo que nos atribui um certo tipo de tarefas contraditórias: receber, atender, acolher aquilo que nos chega e, ao mesmo tempo, ter que refazê-lo, ter que reinterpretá-lo (SKLIAR, 2008). Ou seja, toda transmissão educativa 
transforma o que ela transmite e ao mesmo tempo transforma o emissor e o destinatário e as condições dessa transmissão (FORQUIN, 2003).

\section{REFERÊNCIAS}

AREND, Silvia Fávero. Meninas: trabalho, escola e lazer. In: PINSKY, C. B.; PEDRO, J. M. Nova história das mulheres no Brasil. São Paulo: Contexto, 2013.

BRASIL. Base Legal do Programa Nacional Mulheres Mil: educação, cidadania e desenvolvimento sustentável. Brasília: s.d. Disponível em:

<https://map.mec.gov.br/projects/mulheres-mil/documents>. Acesso em: set. 2016.

Guia metodológico do sistema de acesso, permanência e êxito. Disponível em:

<https://map.mec.gov.br/projects/mulheres-mil/documents>. Acesso em: set. 2016.

III Plano Nacional de Políticas para as Mulheres. Brasília: Presidência da República. Secretaria de Políticas para as Mulheres, 2013.

. Ministério do Desenvolvimento Social e Combate à Fome. O Brasil sem miséria. Organizado por Tereza Campello, Tiago Falcão, Patrícia Vieira da Costa. Brasília: MDS, 2014.

. Lei n. 13.005 de 25 de Junho de 2014. Presidência da República. Casa Civil. Plano Nacional de Educação - PNE. Disponível em:

<http://www.planalto.gov.br/CCIVIL_03/_Ato2011-2014/2014/Lei/L13005.htmm>. Acesso em: 17 ago. 2016.

. Lei n. 9394/96 de 20 de dezembro de 1996. Presidência da República. Casa Civil. Diretrizes e Bases da Educação Nacional. Disponível em:

<http://www.planalto.gov.br/ccivil_03/leis/L9394.htm>. Acesso em: 06 set. 2016.

. Pronatec, Brasil Sem miséria, mulheres mil, Brasília: MDS, MEC, 2014. Disponível em: <https://map.mec.gov.br/projects/mulheres-mil/documents>. Acesso em: 11 set. 2016.

Proposta de Projeto Mulheres Mil: educação, cidadania e desenvolvimento

sustentável. Association of Canadian Community Colleges, Canadá e Ministério da Educação. Secretaria de Educação Profissional e Tecnológica, Brasil, 2006.

. Síntese dos Indicadores Sociais. Uma análise das condições de vida da população brasileira 2015. Rio de Janeiro: Ministério do Planejamento, Orçamento e Gestão. Instituto Brasileiro de Geografia e Estatística - IBGE. Diretoria de Pesquisas. Coordenação de População e Indicadores Sociais. Estudos e Pesquisas e Informação Demográfica e Socioeconômica 35, 2015. Disponível em:

<http://biblioteca.ibge.gov.br/visualizacao/livros/liv95011.pdf>. Acesso em: 05 fev. 2016.

. Síntese dos Indicadores Sociais. Uma análise das condições de vida da população brasileira 2014. Rio de Janeiro: Ministério do Planejamento, Orçamento e Gestão. Instituto Brasileiro de Geografia e Estatística - IBGE. Diretoria de Pesquisas. Coordenação de

Revista Reflexão e Ação, Santa Cruz do Sul, v. 25, n. 2, p. 233-249, Maio./Ago. 2017.

http://online.unisc.br/seer/index.php/reflex/index 
População e Indicadores Sociais. Estudos e Pesquisas e Informação Demográfica e Socioeconômica 34, 2014. Disponível em <http://biblioteca.ibge.gov.br/visualizacao/livros/liv91983.pdf>. Acesso em: 05 mar. 2015.

CAMPELLO, T.; FALCÃO, T. O fim da miséria é só um começo. In: BRASIL. Ministério do Desenvolvimento Social e Combate à Fome. O Brasil sem miséria. Organizado por Tereza Campello, Tiago Falcão, Patrícia Vieira da Costa. - Brasília: MDS, 2014.

DEL PRIORE, Mary. Conversas e histórias de mulher. São Paulo: Planeta, 2013.

FERNANDES, José Henrique Paim. Acesso à Educação e Combate à Desigualdade: o papel da educação no âmbito do Plano Brasil Sem Miséria. In: BRASIL. Ministério do Desenvolvimento Social e Combate à Fome. O Brasil sem miséria. Organizado por Tereza Campello; Tiago Falcão; Patrícia Vieira da Costa. Brasília: MDS, 2014. Disponível em: <http://www.mds.gov.br/webarquivos/publicacao/brasil_sem_miseria/livro_o_brasil_sem_mi seria/livro_obrasilsemmiseria.pdf >. Acesso em: 17 set.2016.

FERRARO, Alceu Ravanello. Analfabetismo no Brasil: desconceitos e políticas de exclusão. Perspectiva, Florianópolis, v. 22, n. 1, jan./jun. 2004. Disponível em: <https://periodicos.ufsc.br/index.php/perspectiva/article/viewFile/10086/9311>. Acesso em: 9 set. 2016.

FISCHER, Rosa Maria Bueno. Trabalhar com Foucault: arqueologia de uma paixão. Belo Horizonte: Autêntica Editora, 2012.

. Foucault e a análise do discurso em educação. Cadernos de Pesquisa, São Paulo: Fundação Carlos Chagas, n. 114, p. 197-223, nov. 2001. http://dx.doi.org/10.1590/S010015742001000300009

FORQUIN, Jean-Claude. Relações entre gerações e processos educativos: transmissões e transformações. In: CONGRESSO NACIONAL CO-EDUCAÇÃO DE GERAÇÕES; 2003, São Paulo. Anais do Congresso Nacional Co-educação de Gerações. São Paulo: SESC, 2003. Disponível em: 〈http://www.sescsp.org.br/sesc/images/upload/conferencias/83.rtf>. Acesso em: 15 jan. 2016.

FOUCAULT, Michel. A ordem do discurso. Tradução Laura Fraga de Almeida Sampaio. 5. ed. São Paulo: Loyola, 1999.

MEYER, Dagmar Estermann. Teorias e Políticas de Gênero: fragmentos históricos e desafios atuais. Revista Brasileira de Enfermagem, Brasília, Associação Brasileira de Enfermagem, v. 57, n.1, p. 13-18, jan./fev. 2004. http://dx.doi.org/10.1590/S0034-71672004000100003

MORAES, Marileia Gollo de. Mulheres das classes populares: histórias e saberes. 2005. 176 f. Dissertação (Programa de Pós-Graduação em Educação - Mestrado) - Universidade Federal do Rio Grande do Sul, Porto Alegre.

ONU MUJERES. Sección Comunicaciones y Promoción. Informe Anual 2014 - 2015. Disponível em: <http://www.onumulheres.org.br/wpcontent/uploads/2013/01/annual_report_SP_2014_2015.pdf>. Acesso em: 6 out. 2016. 
RIBEIRO, Vera Masagão. Alfabetismo funcional: referências conceituais e metodológicas para a pesquisa. Educação e Sociedade, Campinas: Centro de Estudos Educação e Sociedade, ano XVIII, n. 60, dez. 1997.

ROSEMBERG, Fúlvia. Mulheres educadas e a educação das mulheres. In: PINSKY, C. B.; PEDRO, J. M. Nova história das mulheres no Brasil. São Paulo: Contexto, 2013.

SCHÜTZE, Fritz. Pesquisa biográfica e entrevista narrativa. In: WELLER, W.; PFAFF, N. (Org.). Metodologias da pesquisa qualitativa em educação. 3. ed. Petrópolis, RJ: Vozes, 2013.

SCHWENGBER, Maria Simone Vione. Donas de si? A educação dos corpos grávidos no contexto da Pais \& Filhos. 2006. 192 f. Tese (Programa de Pós-Graduação em Educação, Doutorado em Educação) - Universidade Federal do Rio Grande do Sul, Porto Alegre. . Informação verbal. Orientação individual. Unijuí: Ijuí, 2015.

SKLIAR, Carlos (Org.). Derrida \& a Educação. Belo Horizonte: Autêntica, 2008.

SOIHET, R.; PEDRO, J. M. A emergência da pesquisa da História das Mulheres e das Relações de Gênero. Revista Brasileira de História, São Paulo: Associação Nacional de História, v.27, n 54, 2007. http://dx.doi.org/10.1590/S0102-01882007000200015

TELLES, Norma. Escritoras, escritas, escrituras. In: DEL PRIORE, Mary (Org.) História das mulheres no Brasil. 10. ed. São Paulo: Contexto, 2013.

TOMIZAKI, Kimi. Transmitir e herdar: o estudo dos fenômenos educativos em uma perspectiva intergeracional. Educação e Sociedade, Campinas, Centro de Estudos Educação e Sociedade, v. 31, n. 111, abr./jun. 2010._http://dx.doi.org/10.1590/S010173302010000200003 